\title{
Tuning to Odor Solubility and Sorption Pattern in Olfactory Epithelial Responses
}

\author{
John W. Scott, ${ }^{1 \star}$ Lisa Sherrill, ${ }^{1}$ Jianbo Jiang, ${ }^{2}$ and Kai Zhao ${ }^{2 \star}$ \\ ${ }^{1}$ Department of Cell Biology, Emory University School of Medicine, Atlanta, Georgia 30322, and ${ }^{2}$ Monell Chemical Senses Center, Philadelphia, \\ Pennsylvania 19104
}

Odor information is first represented as a spatial activation pattern across the olfactory epithelium, when odor is drawn into the nose through breathing. This epithelial pattern likely results from both the intrinsic olfactory sensory neuron (OSN) sensitivity and the sorptive patterns imposed by the interaction of nasal aerodynamics with physiochemical properties of odorants, although the precise contributions of each are ill defined. Here, we used a computational fluid dynamics (CFD) model of rat nasal cavity to simulate the nasal aerodynamics and sorption patterns for a large number of odorants, and compared the results with the spatial neural activities measured by electro-olfactogram (EOG) under same flow conditions. The computational and experimental results both indicate greater sorption and response to a narrow range odorants as a function of their mucosal solubility, and this range can be further modulated by changes of intranasal flow rates and direction (orthonasal vs retronasal flow). A striking finding is that the profile of intrinsic EOG response measured in surgically opened nose without airflow constraints is similar to the shape of the sorption profile imposed by nasal airflow, strongly indicating a tuning process. As validation, combining the intrinsic response with the mucosal concentration estimated by CFD in nonlinear regression successfully accounts for the measured retronasal and orthonasal EOG response at all flow rates and positions. These observations redefine the role of sorption properties in olfaction and suggest that the peripheral olfactory system, especially the central zone, may be strategically arranged spatially to optimize its functionality, depending on the incoming stimuli.

Key words: computational fluid dynamics; electro-olfactogram; olfactory sensory neuron; rat

\section{Introduction}

Modeling of airflow in the rodent nose has contrasted a central recess of the olfactory epithelium, where airflow is high, with a larger lateral region that has substantially lower airflow (Kimbell et al., 1997; Yang et al., 2007; Jiang and Zhao, 2010). The contours of the flow patterns in these models correspond to the longitudinal mapping pattern of many receptor genes (Ressler et al., 1993; Vassar et al., 1993; Iwema et al., 2004; Miyamichi et al., 2005). The contours of odorant response also follow that pattern (Scott et al., 1996, 1997, 2000, 2006; Scott and Brierley, 1999; Coppola et al., 2013). Recent reviews suggest that this correspondence is driven by the patterns of sorption in the nose that determine the odorant concentration reaching the receptors (Schoenfeld and Cleland, 2005, 2006; Scott, 2006; Wachowiak, 2011). However, existing data and models are not detailed about this sorption process and

\footnotetext{
Received Aug. 31, 2013; revised Nov. 26, 2013; accepted Dec. 14, 2013.

Author contributions: J.W.S. and K.Z. designed research; L.S. and J.J. performed research; J.W.S. and K.Z. analyzed data; J.W.S. and K.Z. wrote the paper.

This work was supported by National Institutes of Health (NIH) Grants DC-00113 (to J.W.S.), R03 NIH 5R03DC008187 (to K.Z.), and 1S10RR024583-01 (to the PennVet Imaging Core). We thank William Goolsby for instrument construction.

*J.W.S. and K.Z. contributed equally to this work.

Correspondence should be addressed to either of the following: John W. Scott, Department of Cell Biology, Emory University School of Medicine, Atlanta, GA 30322. E-mail: jscott@emory.edu; or Kai Zhao, 3500 Market St., Philadelphia,PA 19104.E-mail: kzhao@monell.org; Zhaok@alumni.upenn.edu.

DOI:10.1523/JNEUROSCI.3736-13.2014

Copyright $\odot 2014$ the authors $\quad 0270-6474 / 14 / 342025-12 \$ 15.00 / 0$
}

cannot differentiate sorption from the "inherent patterns" of receptor neuron sensitivity.

One important issue is how to estimate odorant sorption. The original experiments on sorption effects measured the retention time on a polar gas chromatographic column (Mozell, 1964, 1970) or frog nasal cavity (Mozell and Jagodowicz, 1973) to estimate sorption. Kurtz et al. (2004) passed odorant through human noses to measure the difference in concentration of odorant entering and leaving the nose. Other discussions of these issues have largely avoided experimental determinations of mucosal sorption, instead relying on calculations of solubility for odorant molecules (Schoenfeld and Cleland, 2005, 2006; Scott et al., 2006, 2007; Scott, 2006; Yang et al., 2007). Some of these discussions ignore the observations that water solubility does not completely account for sorption (Hornung et al., 1987) and fail to address the anatomical complexities of the airflow path in the nose.

In this report, we compare the electro-olfactogram (EOG) sizes in medial and lateral parts of the olfactory epithelium to simulations of local odorant mucus concentration based on computerized fluid dynamics (CFD). The three datasets address three different issues. First, the concentrations of odorants in the local epithelium were estimated with the CFD calculation based on an anatomically accurate model and nasal aerodynamics simulation. Second, the intrinsic response of the population of OSNs in local regions was estimated by EOGs recorded in the opened preparation, where odor is directly puffed onto the epithelium. Third, EOGs in the intact nose measured the combined effect of the 
A
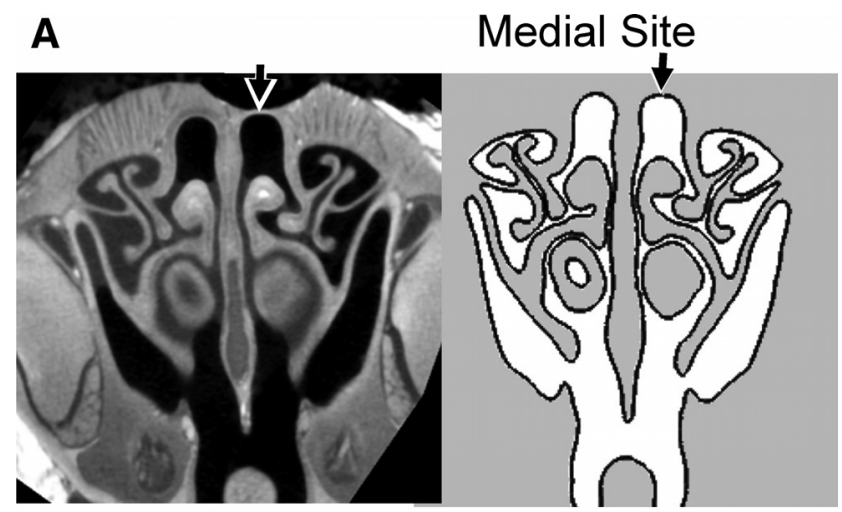

B

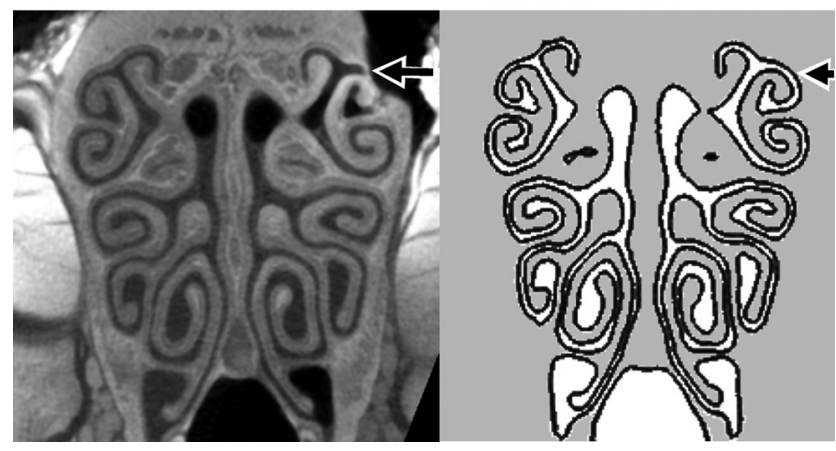

Figure 1. Computed tomography (CT) scans and the construction of the anatomical model. The full set of scans, consisting of 3300 images at an isotropic spatial resolution of $19 \mu \mathrm{m} / \mathrm{pixel}$, were used to construct the anatomically accurate (FD model (see Materials and Methods). The sections on the right side are cross sections of the final CFD model at same location of example CT scans on the left. The lumen of the nasal cavity is shown in white. $A, B$, Arrows indicate the medial $(\boldsymbol{A})$ and lateral $(\boldsymbol{B})$ recording sites. The defects in the bone around those sites show how the bone was locally thinned to allow access to the epithelium.

intrinsic response of the epithelium and the odorant sorption process with the constraints of nasal aerodynamics at four flow conditions. Finally we reconciled these measurements by combining the CFD concentration estimates and open preparation intrinsic response estimates in a regression equation to predict the intact EOG responses for the various flow conditions.

\section{Materials and Methods}

Surgery. All animal procedures followed the protocol approved for this project by the Emory University Institutional Animal Care and Use Committee. Male Sprague Dawley rats weighing 260-560 g were killed by overdose with $100 \mathrm{mg} / \mathrm{kg}$ sodium pentobarbital or with $0.6 \mathrm{ml} / \mathrm{kg}$ Euthanasia III Solution (Med-Pharmex). Death was almost immediate. Afterward, the rat was held with its head up for $\sim 5 \mathrm{~min}$ to allow nasal secretions to drain. A Teflon cannula was inserted into the retronasal space to control airflow through the nose. For intact recordings, the rat was mounted in a stereotaxic device for surgery. For intact recordings, small regions of the olfactory epithelium were exposed on dorsomedial and dorsolateral sites (Fig. $1 A, B$ ) by carefully drilling through the bone until the softer tissue of the epithelium was encountered. The holes were kept as small as possible to avoid removing support for the epithelium leading to collapse that would close the passage. For exposed epithelium recordings, the right side of the nasal cavity was dissected away to expose the nasal septum. Then the septum and the epithelium on the left side were carefully dissected to expose the epithelium overlying the turbinate bones on the left. A flow of isotonic saline was immediately instituted across the exposed epithelium to prevent drying. Four electrodes were placed at equal distances across the rostral border of endoturbinate IV for recordings (Fig. 1B).

Odor stimulation. Odor stimuli were placed in $100 \mathrm{ml}$ bottles fitted with Teflon input and outlet tubes through a Teflon stopper secured by a plastic bottle cap. Most stimuli were diluted 1:10 in mineral oil, and $5 \mathrm{ml}$ of the solution was placed in the bottom of the bottle. This solution had a surface area of $\sim 6 \mathrm{~cm}^{2}$. Materials that were solid at room temperature (e.g., vanillin and camphor) were not diluted, but approximately the same volume was used. The odor bottles were tested before use to be sure the connections were tight, and a gas chromatograph was used to test whether the concentration and purity remained the same before and after use. The concentrations in oil do not perfectly determine the concentration in air (Cometto-Muñiz et al., 2003). Therefore, it is important to note that the odorants were not matched for effective intensity. The comparison of open and intact preparations described below help to control for resulting differences in concentration for odorants at the external nares. The odor bottles were used over a period $\leq 21 \mathrm{~d}$ from pretest to post-test (this period varied with volatility of the compound, since testing demonstrated that the concentration declined more quickly for some odorants). For odor stimulation, air was pushed through the odor bottles by a syringe pump at $100 \mathrm{ml} / \mathrm{min}$ and directed into mixing tubes with multiple ports for $\leq 9$ bottles. Separate mixing tubes were used for orthonasal stimulation and retronasal stimulation. The background clean-air flow rate through the mixing tube was $1000 \mathrm{ml} / \mathrm{min}$ for orthonasal stimulation and $500 \mathrm{ml} / \mathrm{min}$ for retronasal stimulation.

For intact nasal cavity recordings, the orthonasal mixing tube outlet was placed $\sim 1 \mathrm{~cm}$ away from the nose to bath the nose in clean or odorized air without a tight fit that would force air into the nose. The retronasal tube was connected by a two-way valve either to the tracheal cannula or to an exhaust. The lower flow rate for retronasal stimulation guarded against mechanical damage from high air pressure that might move the epithelium relative to the electrode. Thus the final dilutions for odorants were a function of the headspace concentration over mineral oil and the air dilution in the mixing tube. Clean air (filtered through calcium sulfate and activated charcoal) was passed through the mixing tubes constantly. Clean air was pulled through the nose between stimuli by periodic $1 \mathrm{~s}$ pulses separated by $1 \mathrm{~s}$ intervals to clear out previous stimuli. Odor was infused into the tube beginning $8 \mathrm{~s}$ before the beginning of data collection to allow odor concentration in the mixing tube to stabilize. One second of data was collected with no airflow before odor stimulation began. Orthonasal stimulation was applied by opening a valve to draw odorized air through the nose at rates of 50,200 , or $500 \mathrm{ml} / \mathrm{min}$ for $2.5 \mathrm{~s}$. These flow rates were determined by resistances in three parallel lines and set for each individual animal. Orthonasal runs consisted of a series of nine odorants at the three nasal flow rates plus unodorized blanks at each flow rate. All odorants for a session were tested at each flow rate before moving to a higher rate. One minute elapsed between each stimulus presentation. This series was presented three times for each animal. A blank and a standard isoamyl acetate stimulus at $500 \mathrm{ml} / \mathrm{min}$ were presented at the beginning of each flow rate series. Retronasal stimulation was tested at only one flow rate. During the $1 \mathrm{~s}$ before retronasal stimulation, there was no nasal airflow. After this period, a valve opened to force odorized air through the retronasal space and the nasal passages for $3 \mathrm{~s}$. A set of three standard orthonasal isoamyl acetate stimuli was tested immediately before and immediately after the retronasal sequence. The orthonasal sequence was always tested first. If time and the animal condition allowed after the retronasal sequence, the orthonasal sequence was repeated for some experiments. When repeated at $3 \mathrm{~h}$ intervals, absolute response sizes usually diminished, but the relative responses to different odorants remained the same.

For the exposed epithelium recordings, the system was modified slightly. The output of the odor mixing tube was directed toward the epithelium through an $8 \mathrm{~mm} \mathrm{~T}$ connector. The tip of this $\mathrm{T}$ connector was placed $\sim 1 \mathrm{~cm}$ from the epithelium. Suction was applied to the other side of the $\mathrm{T}$ connector at a rate just higher than $500 \mathrm{ml} / \mathrm{min}$ to draw away odorized air. Turning off this suction produced a sharp odor onset and reliable EOG latency. In these experiments only one concentration and flow rate was used.

Recording and data analysis. Micropipettes were filled with isotonic saline and broken to a resistance of $<20 \mathrm{M} \Omega$. For intact nasal cavity recordings, electrodes were driven through the epithelium until a large negative EOG response was encountered to a test stimulus of isoamyl acetate. The electrode depth was adjusted until that response was maxi- 
mal. For exposed epithelium recordings, the electrodes were lowered until the first electrical contact was made with the epithelium. EOG responses were digitized at $1000 \mathrm{~Hz}$ and stored along with records of the odorant stimuli.

The data files were edited and analyzed with standard Matlab (Mathworks) routines or routines written in the laboratory. In some animals, one or two of the replicates of each odor-flow rate pairing was removed if visual inspection showed an artifact that was large enough to alter the reading of response peak or area under the curve of the response or if the response completely failed (i.e., fell to the level of a blank for a stimulus that usually produced a large response in other trials). The size of the response (other than a complete failure) was not a criterion for editing. Because unodorized air sometimes produced artifactual responses, blank responses at each flow rate were routinely subtracted from the odorant trials. After editing, all orthonasal responses were normalized to the mean of the standard isoamyl acetate response immediately preceding and following in the same run of stimuli. For retronasal stimuli, the normalization was to the mean of the series of orthonasal standards that immediately preceded and followed the set of retronasal stimuli. Isoamyl acetate was chosen as the normalizing stimulus because it evoked large, reliable responses at both sites (Scott and Brierley, 1999). Data were analyzed for all odorants that were successfully tested in $\geq 6$ animals with $\geq 4$ tests at each condition. The one exception to this was t-butyl alcohol, for which there were only four animals. Pearson correlation coefficients were used except where identified. The significance level for statistical comparisons was set as $p<0.01$. The false discovery method (CurranEverett, 2000) was used in cases of multiple comparisons. We used the partial correlation procedure for comparing the strength of correlation between correlated variables.

Model construction and simulation. A three-dimensional model of the nasal cavity and nasopharynx was constructed based on one of the rats used for the intact EOG recordings. After the recording session, the head was fixed in formaldehyde (4\%) and shipped to the Monell Chemical Senses Center, where it was sealed in Parafilm and scanned (Viva CT 40 microCT scanner, Scanco USA). The specimen placement and angle were adjusted to place the nasal cavity within the widest viewing field of the scanner ( $45 \mathrm{~mm}$ diameter). Several $\mathrm{x}$-ray bulb voltage and current settings were sampled to produce the best image quality. The final parameters were $70 \mathrm{kV}$ and $114 \mu \mathrm{A}$. A total of 3300 images $(2048 \times 2048$ pixels with an isotropic resolution of $19 \mu \mathrm{m} /$ pixel) were collected using a $3 \mathrm{D}$ median mask of $5 \times 5 \times 7$ pixels to reduce noise and preserve the image of the interface between airway and mucosa, which were segmented using AMIRA software (Visualization Sciences Group; Zhao et al., 2004, 2006). A second commercial software package (grid generator), ICEM (Ansys), was used to generate nasal airway meshes using tetrahedral elements. The boundary-adaptive mesh refinement feature of FLUENT (Ansys) was used to refine cells near the nasal wall to resolve the boundary layer where odorant molecules and particles get trapped and where most heat exchange and mass transport occurs.

The CFD simulation employed routine assumptions from studies of human and rat nasal airflow (Zhao et al., 2006). The nasal wall was assumed to be rigid and smooth, with no slip condition (zero velocity), a static nostril with no movement. Uniform velocity was specified at the inlet while pressure outlet was used at the outlet. Airflow is assumed to be quasisteady, laminar, incompressible, and Newtonian. Finally, the steady-state odorant transport through airflow and mucosal uptake of vaporized odorant that was used in EOG experiments was simulated based on the calculated airflow field and the estimated physicochemical properties (Kurtz et al., 2004). In short, odorant concentration at the boundary of air mucus interface satisfied the following formula:

$$
\frac{\partial C^{\prime}}{\partial y^{\prime}} K C^{\prime}=0
$$

with

$$
K=\frac{d_{i n} D_{m}}{D_{a} \beta H_{m}},
$$

where $d_{\text {in }}$ is the hydraulic diameter ( $4 \times$ area/perimeter) of the nostril, $D_{\mathrm{m}}$ is the odorant diffusion coefficient in mucosa, $\beta$ is the air/mucus odorant partition coefficient (defined by the ratio of odorant concentration in air phase to the concentration in mucus at the air-mucus interface), $H_{\mathrm{m}}$ is the thickness of the mucosal layer and also the length of path that odorant molecules need to diffuse through, and $D_{\mathrm{a}}$ represents the diffusivity of odorant molecules through air, which could be determined by Wilke-Chang equation (Welty et al., 1976). A few of these parameters were based on validation in a previous study (Kurtz et al., 2004). In particular, the air/mucus odorant partition coefficient $\beta$ is refined as follows: $\log (\beta)=\log \left(\beta_{\text {water }}\right)-(\log P-1) \times 0.524$, where $\beta_{\text {water }}$ is the air/water odorant partition coefficient and $\log P$ is the $\log$ (octanol/water partition coefficient), both of which were obtained through a U.S. Environment Protection Agency database [Estimation Program Interface (EPI) Suite; www.epa.gov/oppt/exposure/pubs/episuite.htm]. This calculation was based on strong linear relationship $\left(R^{2}=0.81\right)$ between log $P$ and the difference between $\log$ (air/mucus) and $\log$ (air/water) values for the 12 odorants reported by Kurtz et al. (2004). We have data showing that use of $\beta$ improves the outcome over $\beta_{\text {water }}$. For example, we show a correlation of the stronger regression for the intact responses based on $\beta$ values $(r=0.86)$ than with values based on $\beta_{\text {water }}(r=0.66)$.

\section{Results}

\section{CFD calculations of concentration in epithelium}

The nasal air and odorant flows were simulated replicating the experimental flow rates $(50,200,500 \mathrm{ml} / \mathrm{min}$ for orthonasal, and $500 \mathrm{ml} / \mathrm{min}$ for retronasal) and arbitrarily assuming concentrations of $100 \mathrm{ppm}$ in the inspired air for all odorants (Table 1). These nominal concentrations in the inspired air were not achieved in the physiological experiments. Since the odorant transport and absorption equation is linear, absorption can be linearly scaled to the incoming odorant air concentration; in other words, if the air phase odorant concentration increased from 100 to $200 \mathrm{ppm}$, the absorption everywhere would double. Thus, we can use absorption at a fixed arbitrary concentration (100 ppm) to reflect the specific conductiveness from the external nares to the olfactory region.

The location of the electrode sites in the model was determined using the CT scans (Fig. 1) from one of the animals after EOG recording. The CFD calculations show that absorption of odorants varies spatially as a function of odorant solubility, nasal flow rates, and flow directions (orthonasal vs retronasal), as illustrated for the medial and lateral EOG recording sites. The calculations in Figure 2 were based purely on the nasal anatomy and physical chemistry properties of the odorants, without taking the EOG data into account. It is important to note that the calculated mucosal concentrations were never zero, as it might appear in this figure. One important variable is the odorant air/mucus partition coefficient, which was derived through previous published data (see Materials and Methods for details). At high orthonasal flow rates, the absorbed concentrations peak at intermediate mucosal solubility. The reason for this is shown in the parasagittal plots of odorant sorption (Fig. 2B). For extremely insoluble odorants (e.g., cyclohexane; Table 1, \#62), there is little sorption anywhere in the nasal cavity, and most of the odorant remains in the airway (Fig. $2 A$, inset). Therefore, little anterior-to-posterior gradient of odorant disposition exists. Because of the extreme insolubility of these odorants, their sorption is not affected by airflow rate. On the other hand, extremely soluble odorants (e.g., heptanoic acid, \#6) are strongly sorbed so that many of the molecules are removed from the air phase before they reach the recording site. This upstream depletion effect is partly overcome at high flow rates, which reduce the time for upstream interaction with the nasal cavity surface. Odorants of intermediate solubility (e.g., 2-heptanone, \#40) have an optimal balance between the amount 
Table 1. Odorants used in this study arranged in order of the log of the calculated air/mucus partition coefficient

\begin{tabular}{|c|c|c|c|c|c|c|c|}
\hline Number & Odorant & $\begin{array}{l}\text { Log(air/mucus } \\
\text { partition } \\
\text { coefficient) }\end{array}$ & $\begin{array}{l}\text { Chemical Abstracts } \\
\text { Service (CAS) } \\
\text { registry number }\end{array}$ & Number & Odorant & $\begin{array}{l}\text { Log(air/mucus } \\
\text { partition } \\
\text { coefficient) }\end{array}$ & $\begin{array}{l}\text { Chemical Abstracts } \\
\text { Service (CAS) } \\
\text { registry number }\end{array}$ \\
\hline 1 & Vanillin & -7.191 & $121-33-5$ & 34 & Octanone & -2.9731 & $111-13-7$ \\
\hline 2 & Methyl pyridone & -5.9962 & $694-85-9$ & 35 & Methyloctanoate & -2.9464 & $111-11-5$ \\
\hline 3 & Methyl isonicotinate & -5.7353 & $2459-09-8$ & 36 & Cyclohexylacetate & -2.912 & $622-45-7$ \\
\hline 4 & Octanoic acid & -5.7213 & $124-07-2$ & 37 & Methylcyclohexane carboxylate & -2.912 & $4630-82-4$ \\
\hline 5 & Nonanoic acid & -5.693 & $112-05-0$ & 38 & Phenyl acetate & -2.8866 & $122-79-2$ \\
\hline 6 & Heptanoic acid & -5.4656 & $111-14-8$ & 39 & Octanal & -2.7922 & $124-13-0$ \\
\hline 7 & Hexanoic acid & -5.0868 & $142-62-1$ & 40 & Heptanone & -2.7761 & $110-43-0$ \\
\hline 8 & P-anisaldehyde & -4.9669 & $123-11-5$ & 41 & Heptaldehyde & -2.766 & $111-71-7$ \\
\hline 9 & Menthol & -4.7082 & 89-78-1 & 42 & Methyl heptanoate & -2.6752 & $106-73-0$ \\
\hline 10 & Perillyl alcohol & -4.6035 & $536-59-4$ & 43 & Methyl hexanoate & -2.6639 & $106-70-7$ \\
\hline 11 & Ethylacetoacetate & -4.3132 & $141-97-9$ & 44 & Hexanone & -2.6601 & $591-78-6$ \\
\hline 12 & Beta-ionone & -4.2567 & $79-77-6$ & 45 & Hexanal & -2.5508 & $66-25-1$ \\
\hline 13 & Ethylbenzaldehyde & -4.19 & $4748-78-1$ & 46 & Methyl valerate & -2.489 & $624-24-8$ \\
\hline 14 & Hydrocinnamaldehyde & -4.1736 & $104-53-0$ & 47 & Pentanone & -2.4702 & $107-87-9$ \\
\hline 15 & Heptanol & -4.1292 & $111-70-6$ & 48 & Amyl acetate & -2.4038 & $123-92-2$ \\
\hline 16 & Fenchone & -4.1198 & $7787-20-4$ & 49 & Anisole & -2.4002 & $100-66-3$ \\
\hline 17 & Pyrazine & -3.927 & $290-37-9$ & 50 & Butyraldehyde & -2.3317 & $123-72-8$ \\
\hline 18 & Hexanol & -3.8021 & $111-27-3$ & 51 & Ethyl butyrate & -2.3218 & $105-54-4$ \\
\hline 19 & Trimethylpyrazine & -3.7991 & $14667-55-1$ & 52 & P-cymene & -2.2855 & $99-87-6$ \\
\hline 20 & Acetophenone & -3.7373 & $98-86-2$ & 53 & Methyl butyrate & -2.2616 & $623-42-7$ \\
\hline 21 & Methyl benzoate & -3.5808 & $93-58-3$ & 54 & Gamma terpinene & -2.2243 & $99-85-4$ \\
\hline 22 & D-carvone & -3.5713 & $2244-16-8$ & 55 & Methyl propionate & -2.1519 & $554-12-1$ \\
\hline 23 & Decanone & -3.5397 & $693-54-9$ & 56 & D-limonene & -2.1164 & $5989-27-5$ \\
\hline 24 & Propanol & -3.5226 & $71-23-8$ & 57 & Toluene & -1.6498 & $108-88-3$ \\
\hline 25 & Butanol & -3.4474 & $71-36-3$ & 58 & Alpha pinene & -1.3141 & $80-56-8$ \\
\hline 26 & Cyclohex anone & -3.4382 & $108-94-1$ & 59 & Vinyl cyclohexane & -0.9878 & $695-12-5$ \\
\hline 27 & Cineole-1-8 & -3.4368 & $470-82-6$ & 60 & Alpha terpinene & -0.8582 & $99-86-5$ \\
\hline 28 & t-Butyl alcohol & -3.4357 & $75-65-0$ & 61 & Isopropylcyclohexane & -0.8005 & $696-29-7$ \\
\hline 29 & Methyl nonanate & -3.3604 & $1731-84-6$ & 62 & Cyclohexane & -0.7389 & $110-82-7$ \\
\hline 30 & Camphor & -3.3451 & $76-22-2$ & 63 & Octane & -0.4943 & $111-65-9$ \\
\hline 31 & Cineole-1-4 & -3.3121 & $470-67-7$ & 64 & Heptane & -0.3753 & $142-82-5$ \\
\hline 32 & Benzaldehyde & -3.2654 & $100-52-7$ & 65 & Decane & -0.1829 & $124-18-5$ \\
\hline 33 & Cyclohexenone & -3.0122 & $930-68-7$ & 66 & Hexane & 0.0532 & $110-54-3$ \\
\hline
\end{tabular}

of odorant remaining in the air phase at the recording site and their ability to dissolve in mucus. Therefore, they are sorbed from the airstream but to a lesser degree than heptanoic acid. The upstream sorption of such odorants can be overcome at a high flow rate. With reduced flow rate, peaks not only diminish but also shift toward the insoluble side of the solubility profile. The calculated concentrations at the right (insoluble) side of the solubility profiles for different conditions all collapse together, as this side of the profile is driven by the limitation of odor solubility, instead of by airflow.

The medial and lateral recesses of the rat olfactory epithelium have different structures, so that the air reaching the lateral spaces flows over a longer path with a large surface area (Jiang and Zhao, 2010). As a consequence, the overall upstream sorption of soluble odorants is greater for the lateral region, and the resulting concentrations at the lateral recording sites are lower. The peak mucosal concentrations at the lateral sites are therefore shifted toward insoluble odorants, as indicated by the vertical dotted line where the $\log$ (air/mucus partition coefficient) equals -3 and also by the fact the peak is shifted to the right side of the data point for 2-heptanone (\#40). Just as for the medial site, the right side of the lateral site profile is limited by odor solubility and the profiles collapse together. Thus the odorant access in the nose is modulated by the aerodynamics, depending upon the sniff velocity and mucosa spatial location.

This varying of sorption patterns as a function of solubility is also shown along the medial wall of the endoturbinate bones that face the septum (Fig. 2B). This shows the concentration in the mucosa for three odorants at the high orthonasal nasal flow rate. These sites are not easily accessible for recording in the intact animal, but they are ideal for the open preparation recording to be discussed later. For soluble odorants, there is a gradient across the endoturbinates from the dorsal-caudal border toward the ventral-anterior border. For simplicity, we will refer to this as a dorsal-to-ventral gradient. That pattern corresponds well with the receptor gene expression pattern described for the rat (Vassar et al., 1993). The four electrode positions for the open preparation recordings are illustrated by arrowheads along the rostrodorsal border of endoturbinate IV.

\section{Intact EOGs compared with calculated concentration}

The EOGs recorded in the orthonasal conditions agreed with the CFD calculations in showing that response tended to be greater for odorants of intermediate solubility in mucus. Figure 3 shows the EOGs recorded for the same 66 odorants in the intact preparation with orthonasal flow rates of 500,200 , and $50 \mathrm{ml} / \mathrm{min}$ and with a retronasal flow at $500 \mathrm{ml} / \mathrm{min}$. The odor pulse duration was $2.5 \mathrm{~s}$ for the orthonasal conditions and $3 \mathrm{~s}$ for the retronasal condition. As described in the methods, these EOGs are normalized to the isoamyl acetate response for $500 \mathrm{ml} / \mathrm{min}$ at each electrode to account for variability across animals and across electrode properties. The median of the non-normalized lateral intact isoamyl acetate responses at this high flow rate was $88 \%$ of the median of the non-normalized medial responses. The CFD 


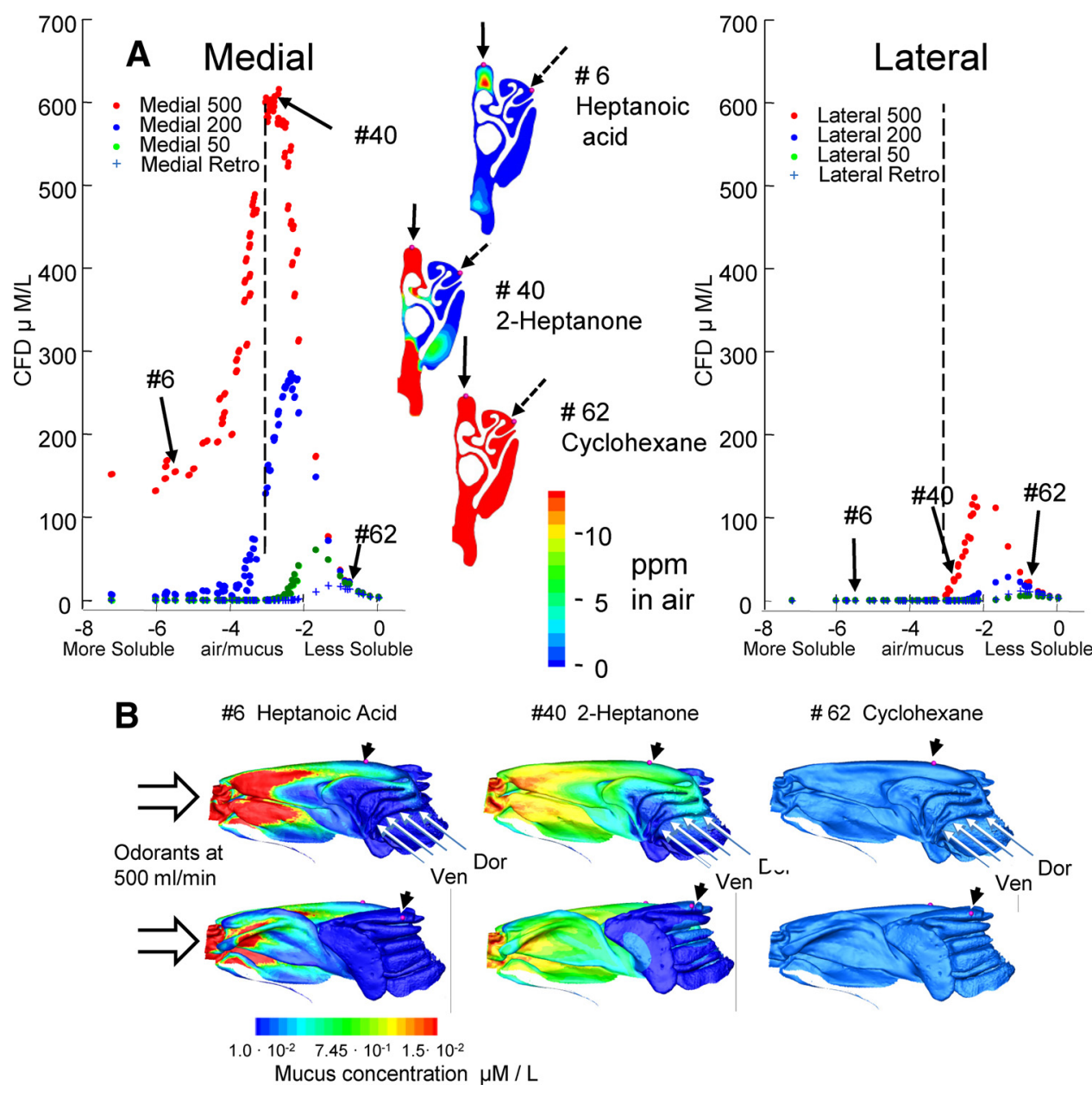

Figure 2. Calculated odorant concentrations in olfactory mucosa under different flow conditions. $A$, The CFD calculations of odorant concentration for the three orthonasal flow rates and for the retronasal condition are shown in the plots on the left and right. The odorants are arrayed on the $x$-axis according to the log of air/mucus partition coefficients in Table 1 . The values for heptanoic acid, 2-heptanone, and cyclohexane are indicated by arrows labeled with the numbers indicating their relative solubility in the mucosa (Table 1, Column 1). The vertical dotted lines corresponding to $\log$ (air/mucus) values of -3 help to indicate the shift in the distributions and the peaks between the two sites. The insets in the center of the panel illustrate the calculated intranasal concentrations in air for coronal sections corresponding to the positions of the medial electrodes at orthonasal $500 \mathrm{ml} / \mathrm{min}$ and incoming odorant concentration at the nostril of $100 \mathrm{ppm}$. The position of the medial electrodes is shown by the solid arrow. The position of the lateral electrodes was more caudal, but the position relative to the midline is shown by the dotted arrow. $\boldsymbol{B}$, The upper row shows the absorbed concentrations in mucus (orthonasal $500 \mathrm{ml} / \mathrm{min}$ and nostril odorant concentration at $100 \mathrm{ppm}$ ) along the turbinate surface as viewed from the septum (top) and viewed from outside (bottom). The arrows at the top of each view in the upper row show the position of the medial electrode. The arrows at the top of each image in the lower row show the positions of the lateral electrodes for the intact preparation. The arrows at the right show the positions of four recording electrodes along the rostral surface of endoturbinate IV used in the open experiments. Rostral is to the left in both the medial and lateral views.

values presented in Figure 3 are also normalized to the calculated isoamyl acetate concentrations at the medial and lateral sites. This normalization scales the EOGs and CFD calculations to the same range of values without any fitting applied between EOG and CFD data. The upper envelope of the EOG responses matches the general shape of the CFD calculations of concentration, especially at high orthonasal flow rates, and the largest orthonasal responses are observed for intermediate solubility odorants.

The peak of the response profile shifted with response position and with flow rate, as predicted by CFD simulation. Compared with the medial responses, the lateral responses were generally larger for insoluble odorants and smaller for soluble odorants (compare with the right and left of the dotted vertical lines), and responses to insoluble odorants were generally larger at lower flow rates. A statistical comparison was made by finding the relative difference between the data for each condition divided by its own mean to adjust for differences in response size, as in the following Equation 1:

$$
\text { Relative size }=\frac{A}{\text { mean }(A)}-\frac{B}{\text { mean }(B)},
$$

where $A$ and $B$ are responses at the medial and lateral sites respectively for comparisons of the shift between sites at each flow rate, or where $A$ and $B$ are responses at the higher and lower flow rates respectively for comparisons of the shift produced by changing flow rate at each site.

When the peak is shifted toward insoluble odorants, this relative size will be bigger for some of the insoluble odorants. We tested for this difference by correlating the relative sizes with the $\log$ (air/mucus partition coefficient). We used the Spearman rank-order correlation $(\rho)$ in this test because the relation between the shift and the mucus solubility is not linear, being greater for intermediate solubility than at the extremes of the profile, so that $\rho$ is more sensitive than the Pearson correlation. These correlations are shown in Table 2. These quantitative differences in EOG response as a function of flow rates support the CFD-predicted shift in odorant concentration. 

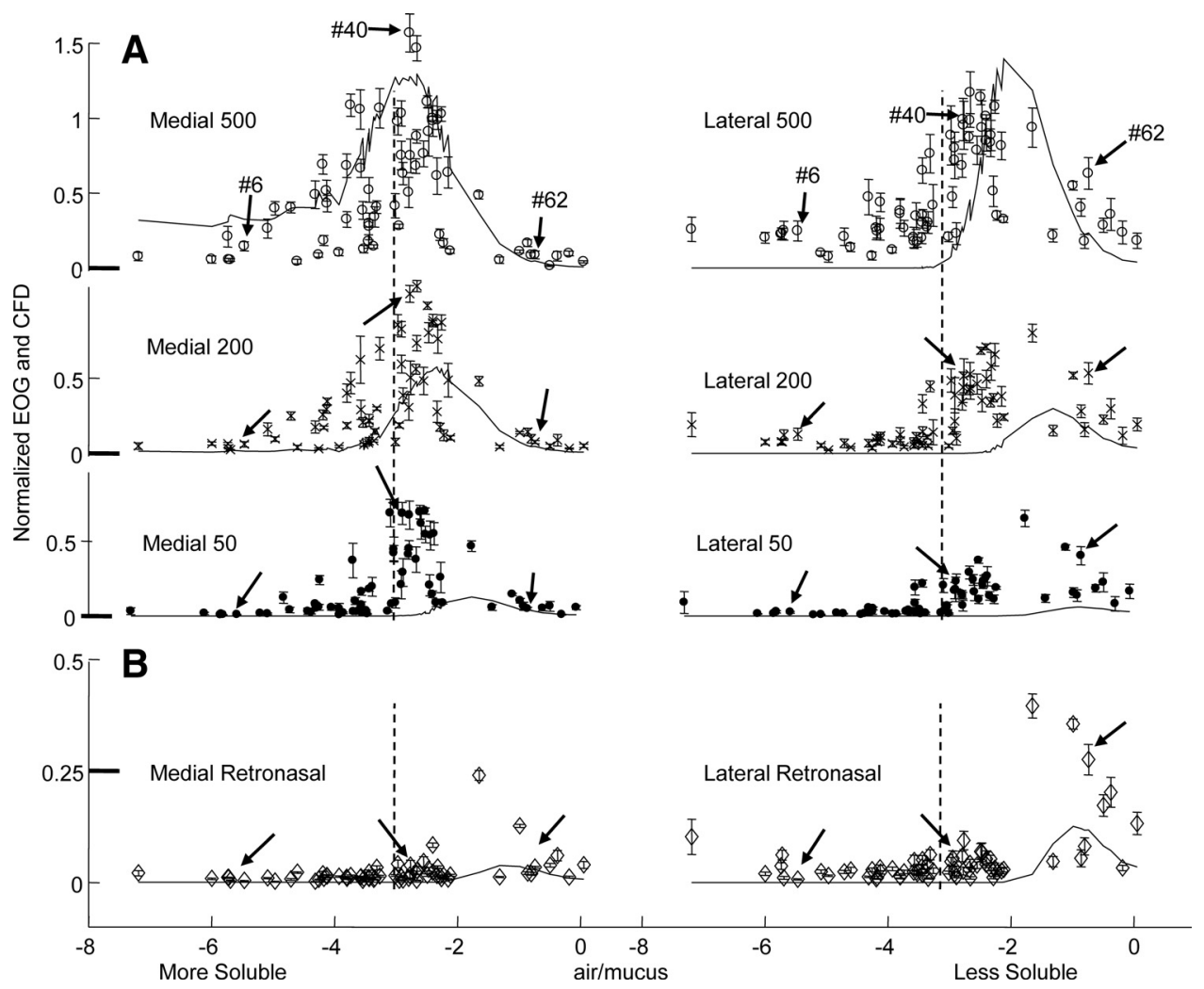

Figure 3. Responses and simulations in the intact preparation. $\boldsymbol{A}, \boldsymbol{B}, \mathrm{EOGs}$ for orthonasal flow at three flow rates $(\boldsymbol{A})$ and for retronasal flow at the highest flow rate $(\boldsymbol{B})$. The symbols indicate the response size relative to the orthonasal isoamyl acetate response at $500 \mathrm{ml} / \mathrm{min} \pm \mathrm{SEM}$ plotted against the log(air/mucus partition coefficient). The lines show the CFD simulation of odorant concentration in the epithelium at the recording sites under each flow condition. The CFD results are normalized to the CFD values for isoamyl acetate at $500 \mathrm{ml} / \mathrm{min}$ at the two sites. The vertical dotted lines, as in Figure $2 A$, help to emphasize the differences between the medial and lateral distributions. Note that the retronasal results are shown at an expanded vertical scale. The arrows in each plot point to the positions of the three odorants identified in Figure 2.

Table 2. Shift comparisons for all conditions

\begin{tabular}{lll}
\hline & $\begin{array}{l}\text { Observed } \\
p \text { value }\end{array}$ & $\begin{array}{l}\text { Required } \\
p \text { value }\end{array}$ \\
\hline Orthonasal comparisons & & \\
Medial $500 \mathrm{ml} / \mathrm{min}$-lateral $500 \mathrm{ml} / \mathrm{min}$ & 0.0007 & $0.00375^{*}$ \\
Medial $200 \mathrm{ml} / \mathrm{min}$-lateral $200 \mathrm{ml} / \mathrm{min}$ & 0.0016 & $0.004375^{*}$ \\
Medial $50 \mathrm{ml} / \mathrm{min}$-lateral $50 \mathrm{ml} / \mathrm{min}$ & 0.0381 & 0.00625 \\
Medial $500 \mathrm{ml} / \mathrm{min}$-medial $200 \mathrm{ml} / \mathrm{min}$ & 0.0000 & $0.0025^{*}$ \\
Medial $500 \mathrm{ml} / \mathrm{min}$-medial $50 \mathrm{ml} / \mathrm{min}$ & 0.0000 & $0.001875^{*}$ \\
Medial $200 \mathrm{ml} / \mathrm{min}$-medial $50 \mathrm{ml} / \mathrm{min}$ & 0.0000 & $0.00125^{*}$ \\
Lateral $500 \mathrm{ml} / \mathrm{min}$-lateral $200 \mathrm{ml} / \mathrm{min}$ & 0.0000 & $0.000625^{*}$ \\
Lateral $500 \mathrm{ml} / \mathrm{min}$-lateral $50 \mathrm{ml} / \mathrm{min}$ & 0.0004 & $0.003125^{*}$ \\
Lateral $200 \mathrm{ml} / \mathrm{min}$-lateral $50 \mathrm{ml} / \mathrm{min}$ & 0.0055 & 0.005 \\
Medial retronasal-lateral retronasal & 0.3788 & 0.00875 \\
Medial $500 \mathrm{ml} / \mathrm{min}$-medial retronasal & 0.1115 & 0.006875 \\
Medial $200 \mathrm{ml} / \mathrm{min}$-medial retronasal & 0.2505 & 0.008125 \\
Medial $50 \mathrm{ml} / \mathrm{min}$-medial retronasal & 0.8374 & 0.01 \\
Lateral $500 \mathrm{ml} /$ min-lateral retronasal & 0.5883 & 0.009375 \\
Lateral $200 \mathrm{ml} / \mathrm{min}$-lateral retronasal & 0.1857 & 0.0075 \\
Lateral $50 \mathrm{ml} / \mathrm{min}$-lateral retronasal & 0.0312 & 0.005625 \\
Retronasal comparisons: log(air/mucus) $>-3$ & & \\
Medial retronasal-lateral retronasal & 0.0275 & 0.00857 \\
Medial $500 \mathrm{ml} /$ min-medial retronasal & 0.0001 & $0.00571^{*}$ \\
Medial $200 \mathrm{ml} /$ min-medial retronasal & 0.0001 & $0.00429^{*}$ \\
\hline * $<0.01 \mathrm{by}$ the flseliscory & &
\end{tabular}

${ }^{*} p<0.01$ by the false discovery criterion.

For the retronasal response, the EOG plots (Fig. 3B) also suggest a shift of retronasal response peaks toward insoluble odorants. This shift is not detected by the same analysis because so many of the more soluble odorants do not evoke much retronasal response. If the 33 most insoluble odorants [i.e., those with $\log$ (air/mucus) partition $>-3$ ] are tested with the correlation of shift versus mucus solubility, the retronasal responses are different from most of the orthonasal responses (Table 2). The differences between orthonasal versus retronasal responses are predicted from the anatomical differences in the flow paths reaching the epithelium in the retronasal versus orthonasal flow paths (Yang et al., 2007).

One explanation of why the EOG variability is greater than the CFD prediction is that there are differences in receptor sensitivity that are not completely dependent on mucosal solubility. Therefore, averaging the response with similar mucus solubility should smooth the EOG profiles and facilitate comparison with the CFD concentration profiles. Figure $4 A, B$ shows the EOG solubility profiles at the highest flow rate for the medial and lateral sites. The accompanying running average is based on odorants with mucosal solubilities in the range of $\pm 0.5 \log$ units. Figure $4 C, D$ plots the solubility profile of the smoothed EOGs and the CFD concentration calculations. The match is very good for both the medial site $(r=0.94, p<0.01)$ and the lateral site $(r=$ $0.74, p<0.01)$.

Comparison of the smoothed results to the nonsmoothed results also allowed us to test whether the EOG variability was systematic. Odorants that evoked larger than the smoothed average responses at the medial recording site also tended to evoke larger than smoothed average responses at the lateral site. This is evidenced by the significant correlation between the residual differences between smoothed and unsmoothed EOGs for the medial site and the residuals for the lateral site $(r=0.57, p<0.01)$. 

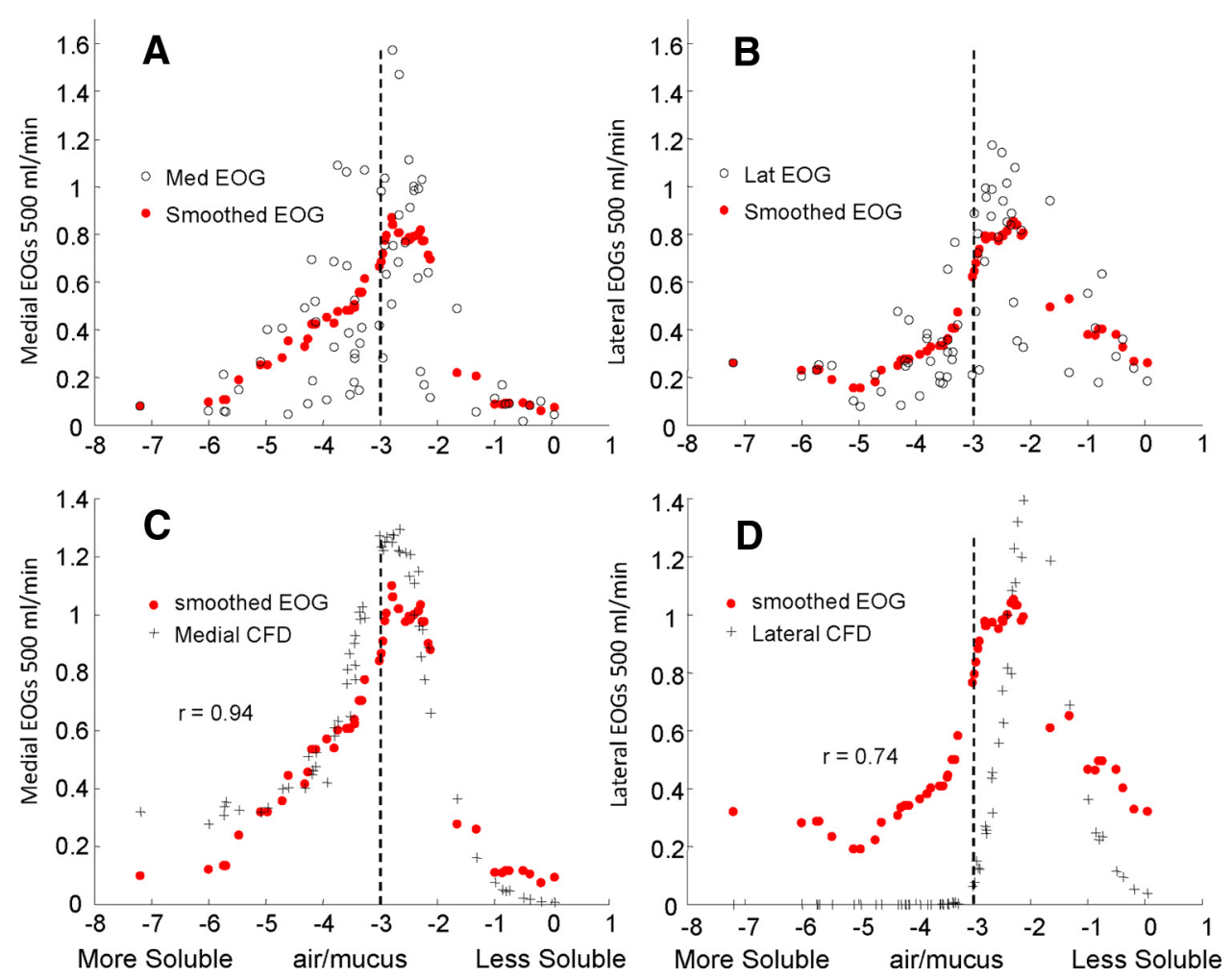

Figure 4. Comparison of smoothed EOG records and odorant concentrations. $A, B$, Intact medial and lateral EOG at orthonasal $500 \mathrm{ml} / \mathrm{min}$ compared with a moving average, where EOG values to odorants with similar mucosa solubility values ( $\pm 0.5 \mathrm{log}$ unit) are averaged. This average serves to remove the variabilities (neuronal, experimental, etc.) that are unrelated to sorption. $\boldsymbol{C}, \boldsymbol{D}$, The moving average response is compared with the CFD-calculated concentrations. In each case, the values are normalized to the value for isoamyl acetate. The vertical dotted lines corresponding to $\log$ (air/mucus) values of -3 help to compare the peaks with those in previous figures.

Thus, the smoothing seems to remove variations in the intrinsic response due either to experimental factors or to differences in receptor response for the odorants. The residuals for the medial and lateral site did not correlate with the vapor pressure or molecular volume of the odorants, suggesting that these molecular properties do not explain the variability.

Aside from the issue of variability, the EOG profiles in Figure 3 differ from the profiles for calculated mucosal concentrations in at least two systematic ways. First, the shift in EOG solubility profile for lower flow rates is smaller than the shift for CFD concentration calculations, showing that the response is not determined solely by the concentration. Second, the relative size of the EOGs does not change linearly with the calculated concentration across flow conditions, consistent with a nonlinear relationship between concentration and response. Both reasons led us to measure the EOG response in the absence of nasal air flow for some of the odorants in our sample and test whether the intrinsic sensitivity along with the calculated concentrations could be used to improve the prediction of the observed EOGs in the intact preparation.

\section{Open preparation EOGs}

We recorded EOGs in the open preparation as an independent assessment of the intrinsic sensitivity of the epithelium to the test odorants at concentrations equal to those at the external naris for the orthonasal condition. Since odorant is directly puffed onto the mucosa in this setup, it removes the nasal airflow constraints. Therefore, whatever comes out of the olfactometer is fully available for absorption. Figure 5 shows the open preparation responses to 35 odorants from the population used in Figures 2 and 3 and compares them to the intact preparation CFD-predicted mucosal concentration. The recording sites along the rostrodorsal border of endoturbinate IV were chosen because they lie across regions expressing the same sets of receptors as the medial versus lateral division of the epithelium and because modeling studies had estimated that this region was subject to the same variation in flow rates as the medial versus lateral division (Fig. 2B). In addition, previous experience (Scott and Brierley, 1999) with this preparation had shown us that response viability and accuracy of electrode placement from animal to animal is easier to achieve along this endoturbinate surface than along the lateral turbinate bones where there are few anatomical landmarks. In Figure $5 A, B$, responses at the dorsal and ventral open sites are also normalized to the isoamyl acetate responses at the same sites. The median of the non-normalized isoamyl acetate responses on the most ventral electrode was $130 \%$ of the non-normalized median of the responses on the most dorsal electrode. We performed an analysis like that of Figure 4 to test whether open preparation responses that differed from the smoothed open response average were the same ones that differed from the smoothed intact response average at the high flow rate. This correlation of residual differences for the dorsal open versus the intact medial sites was significant $(r=0.70, p<0.01)$, as was the correlation of the ventral open versus the intact lateral sites $(r=0.65, p<0.01)$. The open and intact recordings were performed in different animals and used odorant samples prepared at different times. This strengthens the case that the variability had systematic origin.

An important finding in Figure 5 is the similarity between the open response profile and the CFD-computed sorption profile, especially for the dorsal site. The open responses in Figure $5 A, B$ are not constrained by the nasal airflow, but they have similar 

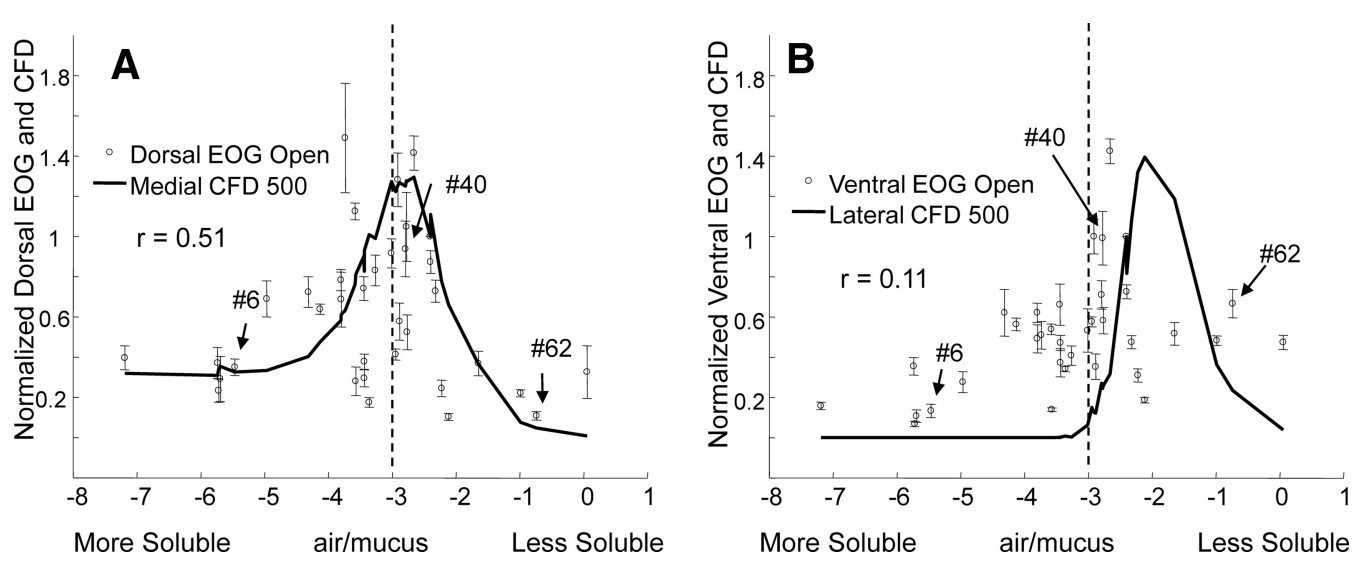

Figure 5. Responses in the open preparation and their comparison with intact responses. $A, B$, The mean responses \pm SEM for the most dorsal and most ventral of the four electrodes in the open preparations for 35 of the odorants shown in Figure $1 B$. The solid line shows the CFD calculations of odorant concentration for the high flow rate scaled to isoamyl acetate response. The vertical dashed line at $\log$ (air/mucus) equals -3 helps indicate the shift in response distributions between the two plots. Odorants are identified as in Figure 1.

profiles to the high flow rate intact responses shown in Figure 3. For example, the open response profiles correlate significantly with the high flow rate intact responses (for dorsal open vs medial intact, $r=0.80, p<0.01$; for ventral open vs lateral intact, $r=$ $0.73, p=0.01)$. The largest responses at both open sites $(5 A, B)$ are for intermediate solubility odorants, although the correlation between the open response and the CFD calculations is significant only for the dorsal site. It is noteworthy that the CFDcomputed concentrations are substantially higher for the intact medial region (comparable to the open dorsal site) than the intact lateral region (comparable to the open ventral site) at all flow rates. Therefore, if there is an influence of odorant concentration on the expression of receptors within a region, it might be substantially greater in the medial region.

In addition, comparison of the dorsal and ventral open sites shows a shift of the ventral site response profile toward insoluble odorants by the analysis of Equation $1(\rho=-0.60, p<0.01)$. This is consistent with the shift of odorant absorption peak predicted by CFD between the two regions. Thus, the similarity of open and high flow rate responses, the significant correlation of the open dorsal with the intact medial CFD concentration calculation, and the significant shift of both open response profiles and odorant absorption toward insoluble odorants for the lateral and ventral sites all suggest the possibility that the intrinsic sensitivity may be driven by the airflow pattern.

This comparison between normalized open and intact responses shows that, even if the nasal aerodynamics shape the intrinsic response, the intact response is determined by both the intrinsic response and the odorant access resulting from the sorption pattern. This point is further emphasized by comparing the open responses in Figure $5 A, B$ with the intact responses in Figure 3 at lower flow rates and at retronasal flow. Since the intrinsic responses do not change at lower flow rates or in the retronasal condition, the intact response profiles should be a combination of the open response and the sorption predicted by CFD and should lie between these two. This reasoning is confirmed in Figure 3 and gives rise to our attempt to quantitatively test this conclusion.

\section{Regression to estimate response functions}

The concept that the intact response is a combination of the intrinsic epithelial response (estimated by the open response) and the mucosal concentration (estimated by CFD) led us to construct a regression model based on these two values. Since the relative size of the EOGs does not change linearly with the calculated concentration across flow conditions, suggesting a nonlinear relationship between concentration and response, the regression model fit the four calculated concentrations for each odorant in the four conditions by assuming that the olfactory response should be sigmoidally related to the logarithm of stimulus concentration as reported in the observations of Grosmaitre et al. (2006) and of Rospars et al. (2008). We used the following logistic equation, Equation 2, to fit the intact response for each odorant:

$$
Y_{\text {Intact }}=\frac{a 1}{1+e^{-a 2 \cdot \log (C F D) \cdot O P E N-a 3}},
$$

where CFD is the CFD-estimated concentration for each odorants and OPEN is the response to each odorant in the open preparation.

In this equation, $a 1$ determines the upper asymptote, $a 2$ determines the slope of the curve at the inflection point, and $a 3$ determines the $x$-axis position of the inflection point. The open response data are used to correct the CFD-estimated concentration for the intrinsic response. When we treated the medial and lateral recording sites separately, only $a 3$ was significantly different between the two sites. Therefore, we used a dummy variable procedure to estimate $a 3$ for each site, while estimating common values for $a 1$ and $a 2$. Figure $6 A$ shows that the response for the four flow conditions (orthonasal 500, 200, and $50 \mathrm{ml} / \mathrm{min}$, plus the retronasal $500 \mathrm{ml} / \mathrm{min}$ ) could be fit successfully with that procedure. The strength of the regression for the total dataset $(r=0.86, p<0.01)$, which is significantly better than the correlations with the open response alone or with the calculated concentrations alone (Table 3 ), indicates that the intact response is a combination of both the intrinsic sensitivity and the absorbed odor concentration.

The question arose of whether the estimates of intrinsic response taken from the open preparation are unique in producing an effective regression. We approached this by resampling the regression equation with random numbers normally distributed around the means of the open response values with $\mathrm{SDs} \leq 2.5$. Only when the SD of the random sample was $<1.0$ did any of 20,000 random samples produce correlations as strong as that observed with the open response data. Maximum correlations of up to $r=0.89$ were obtained with SDs of $<0.5$, suggesting that if there is a set of more optimum values for the intrinsic response, it 

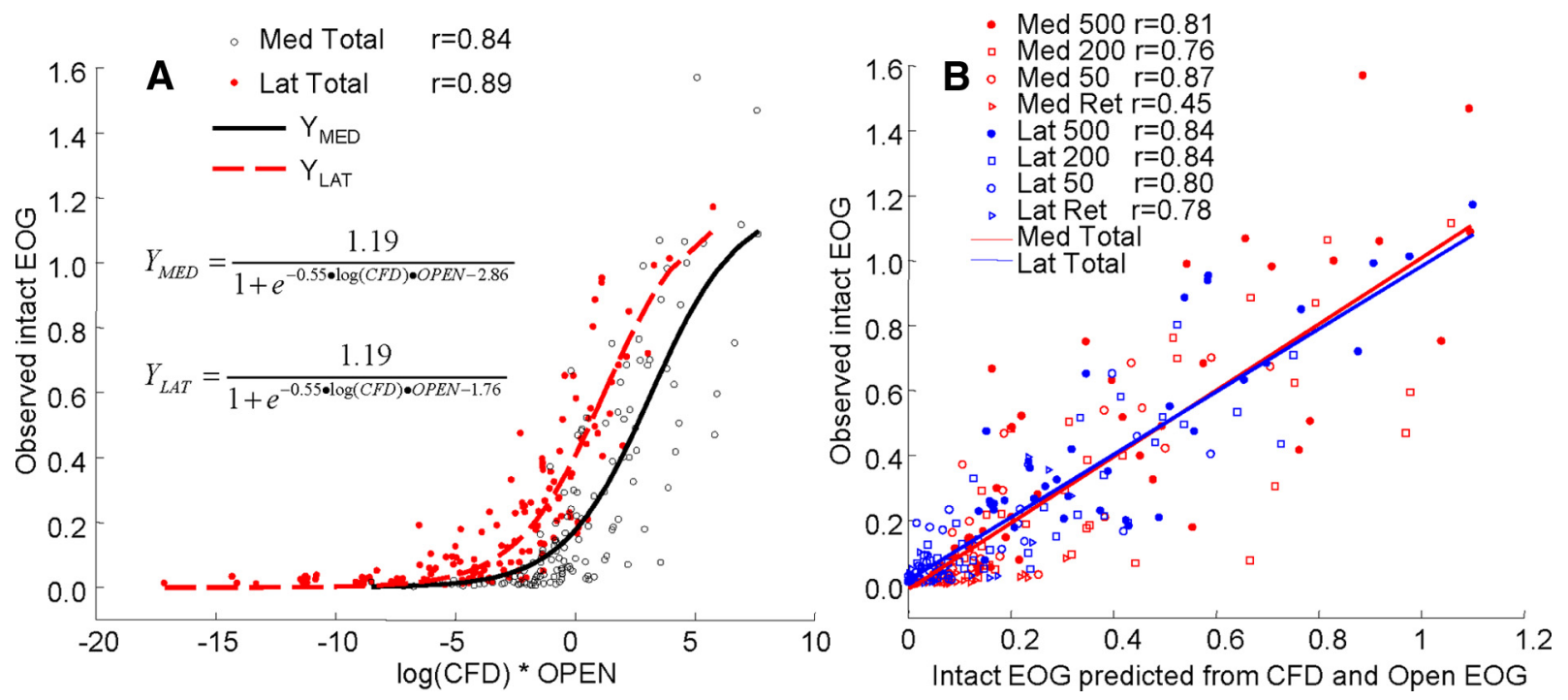

Figure 6. Prediction of intact EOG response by the regression on open response and calculated concentration. $A$, The open responses from Figure $4 A$ and $B$ were used as estimates of the inherent response of the olfactory epithelium to each odorant. These values were entered into a logistic regression equation with the logarithm of the calculated odorant concentration at each flow condition for the two intact sites to predict the intact response. The overall correlation including both sites and all four conditions is $0.86(p<0.001)$. $\boldsymbol{B}$, The data of $A$ are replotted to show that the relationship between predicted and observed values is generally linear. All the correlations in the figure are significant at $p<0.001$ except that for the medial retronasal site for which $p=0.006$.

Table 3. Data showing that the strength of the regression for the total dataset $(r=0.86, p<0.01)$ was significantly better than the correlations with the open response alone or with the calculated concentrations alone

\begin{tabular}{lll}
\hline & $r$ Values & $p$ Values \\
\hline EOGs versus & & \\
Eq. 2 & 0.86 & 0.01 \\
Open & 0.44 & 0.01 \\
CFD & 0.62 & 0.01 \\
Log(CFD) & 0.50 & 0.01 \\
Partial EOGs, Eq. 2, versus & & \\
Open & 0.83 & 0.01 \\
CFD & 0.80 & 0.01 \\
Log(CFD) & 0.81 & 0.01 \\
\hline
\end{tabular}

is close to the ones observed in the open preparation. We also asked whether vapor pressure or molecular volume of odorants could substitute for the open response data. Neither of these values produced correlations $>0.71$ when used in the place of the open response values in Equation 2. Adding vapor pressure or molecular volume to the regression equation as a multiplier of the open response did not improve the fit. We also tested CFD simulations of concentration based on air/water partition rather than air/mucus partition. This simulation was less successful in the regression producing a smaller overall correlation of $r=0.66$ $(p<0.01)$. Further evidence that the air/mucus simulation produces a better fit is the partial correlation between EOGs and the air/mucus simulation adjusting for the effect of the air/water simulation $(r=0.74, p<0.01)$.

The regression result is plotted with observed EOGs versus the predicted response in Figure $6 B$ to emphasize that the quality of the fit across the different flow rates. This plot shows no indication of nonlinearity within each condition. The relationship between the predicted and observed response is present within each flow condition, showing that calculated concentration determines response independent of flow condition. Table 3 compares the correlations for the regression equation correlations for the open response and CFD-calculated concentrations. The resulting intact neural response is a combination of the intrinsic response of the epithelium, governed by the receptor properties, and the odorant concentration.

The results from Equation 2 can also be used to successfully predict the profile shift between the medial and lateral intact responses at the different flow rates and conditions. Figure $7 \mathrm{~A}$ shows the observed versus predicted medial versus lateral response shift at the three orthonasal flow rates. The overall correlation between predicted and observed shifts is $r=0.81$, showing that the predictions of the individual values are robust enough to predict the regional differences. The slopes of the plots for the three flow rates are not significantly different.

The retronasal responses are also well predicted by Equation 2 . Figure $7 B$ presents the total retronasal response normalized to the total orthonasal response for each odorant. The rationale for this normalization is the presentation in our previous report (Scott et al., 2007) and the fact that behavioral studies of retronasal olfaction have compared the orthonasal and retronasal responses. The results show a strong correlation between the predicted and observed responses, which agree in indicating that only extremely insoluble odorants are almost as effective retronasally as they are orthonasally. This indicates that the upstream absorption is much greater in the retronasal direction because the longer flow path promotes sorption of all except the most insoluble odorants.

Overall, our recordings and modeling strongly support the concept that the final neural spatial activities are shaped by both intrinsic and imposed patterns. The results also shed light on the intrinsic response pattern, which is not random, but rather is likely to be tuned by the imposed sorption pattern at high nasal flow rates. Although the observations are limited by the number of recording sites and to steady-state simulations of longduration odor pulses, they clearly support a quantitative approach to the issue of odorant access in the olfactory epithelium.

\section{Discussion}

\section{Impact of nasal structure and air flow on the olfactory response}

The CFD results show that intranasal airflow has strong effects on the olfactory response. The CFD calculations predict that the nasal absorption is maximally tuned to odorants of intermediate 

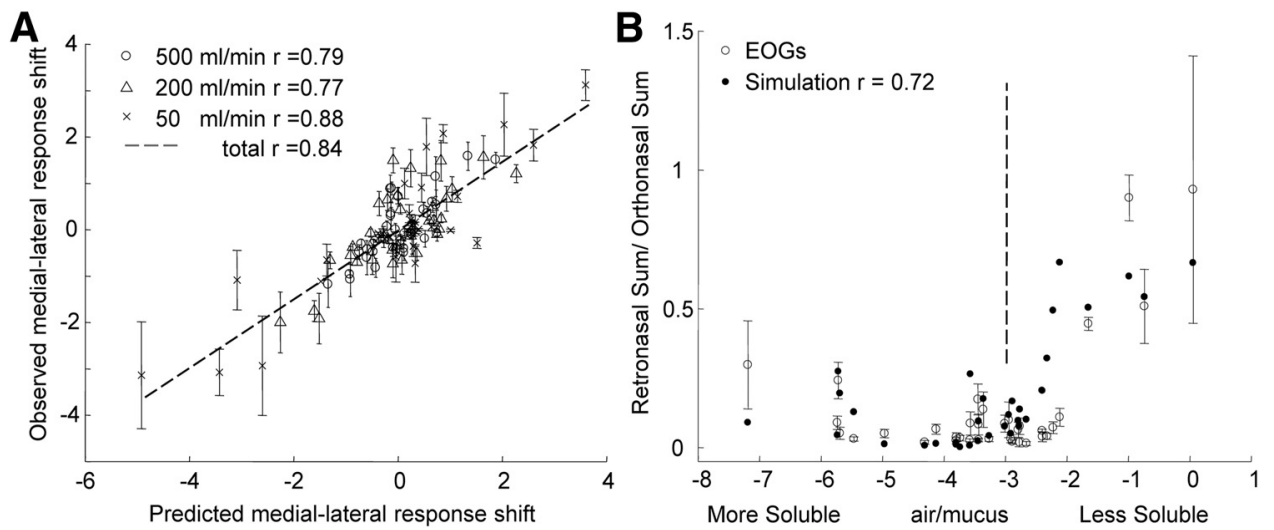

Figure 7. Comparison of predicted response patterns and observed EOGS. A, Differences between the medial and lateral responses at the three orthonasal flow rates plotted against the prediction from the regression of Equation 1. B, Total (medial plus lateral) retronasal EOG response \pm SEM normalized to total orthonasal response at the highest flow rate with the values predicted from total retronasal prediction from Equation 1 divided by the total orthonasal prediction. The vertical dotted line corresponding to $\log$ (air/mucus) values of -3 help to compare the retronasal sum with the values in previous figures.

solubility and this maximum shifts toward lower solubility as the mucosa location moves from dorsal-medial to lateral regions. These profiles show a gas chromatographic-like separation of the odorant concentrations, which depends on the mucosal solubility, flow rate and epithelium position. The effect of position is due to the anatomy that imposes a longer flow path and lower flow rates on the lateral recess.

The intact EOG results showed the same quantitative pattern as the CFD profiles despite the greater scatter in the EOG data points. However, there was a consistent shift of the EOG profile toward larger responses for insoluble odorants for slower flow rates and larger responses to insoluble odorants at the lateral site. The differences between the CFD profile and the intact EOG profile derive from the intrinsic response discussed below.

\section{The intrinsic response estimate}

The intrinsic response as estimated by the open preparation recordings makes two important points. First, even though this response is not constrained by airflow, it still shows substantial similarity to the odorant sorption profile predicted by the CFD model, especially at the medial site and for the comparison of medial and lateral sites. This similarity between the open EOG and intact sorption profiles may represent a tuning of the sensitivity of each mucosa region to the odorants normally available at that region during breathing and active sniffing. The highest flow rate of $500 \mathrm{ml} / \mathrm{min}$ we used was in the upper range of maximal sniff velocity reported by Youngentob et al. (1987). It is likely that these high flow rates, which often occur during olfactory tasks, are more olfactory-relevant flow rates to which the tuning of intrinsic sensitivity is based. This interpretation is supported by the observations of Cenier et al. (2013), who do not see substantial differences in response for soluble odorants across the sniff velocities observed in awake animals.

Second, the variability pattern of the intrinsic response was similar to intact EOG variability. This shows that much of the intact variability is produced by the intrinsic response. There are differences between the intrinsic and intact responses even at the highest flow rates. These differences result from the upstream odorant sorption, which is estimated by the CFD calculation. This interpretation was also supported by the fact that the deviation from the moving average response correlated between corresponding recording sites for the open versus intact preparations.

\section{Relation of estimated concentration to response}

We approached the comparison of the CFD and EOG results by assuming that the neural response is a sigmoidal function of the logarithm of odorant concentration (Grosmaitre et al., 2006; Rospars et al., 2008). We chose the logistic equation rather than the Hill equation because they are mathematically equivalent and the logistic equation is easier to fit in the absence of reliable estimates of the maximum response (Barlow and Blake, 1989). The open preparation data were used as a multiplier of the $\log$ (odorant concentration) to adjust for the relative stimulus potency in activating olfactory sensory neurons (OSNs). This is an approximation because the shape of the stimulusresponse function is not likely to be exactly the same for each receptor. Nevertheless, the regression led to a correlation of 0.86 , accounting for $74 \%$ of the variance in the size of the intact response. This correlation did not result simply from the overall difference in response size between the different flow rates, as is evidenced by the strong correlations within most of the flow conditions. Those predicted values were sufficiently accurate to predict the shift in EOG solubility profile between the two recording sites. This relationship quantitatively explains the relationships in Figure 3, where the size of the EOGs is not linearly related to the CFD concentrations.

The results of this regression have two implications. First, the intact response sizes depend on two conditions: intrinsic response and odorant access. Second, the CFD estimates have to be very accurate for this regression to work well. The success of the CFD calculation is strong evidence for the validity of this model, and supports its extension to other species (Zhao et al., 2006; Lawson et al., 2012). The interpretation of such modeling for other species must face the problem of difficulty in estimating the intrinsic response. The comparison of the open and intact responses demonstrates that the intrinsic response cannot be easily determined from physiological or behavioral measures in an intact organism.

\section{Spatial distribution of response}

The hypothesis that the olfactory epithelium and olfactory bulb responses are organized according to odorant sorption is perhaps most clearly stated by Schoenfeld and Cleland (2006), and is supported by computational models (Zhao et al., 2006; Yang et al., 2007). The general idea that the intrinsic sensitivity is spatially distributed goes back to recordings of OSN activity in salamander 
(Kauer and Moulton, 1974; Moulton, 1976; Mackay-Sim et al., 1982) and rat (Scott and Brierley, 1999), and has been strengthened by the observation that the gene expression zones correspond with the distribution of physiological response in these species (Vassar et al., 1993; Marchand et al., 2004). The current report supports the hypothesis of relation between sorption and spatial distribution of response, but extends it in several ways. The CFD quantification details how the medial and lateral recesses of the olfactory epithelium are anatomically optimized for odorants of different solubilities. We provide evidence for the first time that this sorption optimization effectively tunes these regions to different odorants. The similarity between CFDpredicted sorption profiles and responses in the open preparation strongly suggests that the intrinsic activity is tuned by the pattern of sorption during high nasal flow rates in active sniffing.

\section{Retronasal responses}

The perception of odors presented retronasally is sometimes different from the perception of the same odors presented orthonasally (Sun and Halpern, 2005). There are also cases where odor presentation by the two routes is differentially affected in disease (Landis et al., 2003; Pfaar et al., 2006). Since most odors are mixtures of molecular compounds, differences in sorption of odorants between the two paths could change the proportions of the components of a mixture reaching the receptors. This possibility is recognized in recent publications (Hummel, 2008; Wilkes et al., 2009), but to date there have been relatively few data to show how well sorption patterns might affect retronasal response. Diaz (2004) argued that these differences are correlated with odorant solubility. Wilkes et al. (2009) showed that mucosal solubility is a better predictor than water solubility, but that evidence is available for few odorants. Our data and simulations agree that retronasal responses are significantly reduced and shifted toward the most insoluble odorants, even at a high flow rate. However, it is important to note that these data were collected on rodents for the expiratory phase of the air flow. Zhao et al. (2004) showed using the CFD model that retronasal air flow and odor absorption in human are much more robust than in rodents, and even surpasses orthonasal airflow and odor absorption. Scott et al. (2007) pointed out that expired odorants residual in the nasal cavity can be pulled into the olfactory cleft by subsequent inspiration. It will be important to investigate these effects in models and experiments in different species with inclusion of more natural breathing and sniffing patterns.

The sorption patterns reported here do not account for the entire spatial response in the olfactory bulb, which is further shaped by the projection pattern to the glomeruli (Ressler et al., 1994; Vassar et al., 1994). This pattern can be seen with several glomerular recording techniques (e.g., Johnson et al., 2007). In addition, the steady-state conditions of our study do not account for active sniffing patterns, such as those studied by Cenier et al. (2013). However, the interaction of the sorption pattern with the direction and velocity of intranasal airflow can change the sensitivity of response to individual odorants, and should affect the relative concentration of components of complex mixtures in the retronasal versus orthonasal conditions. The CFD simulation model described and tested here provides a realistic approach toward estimating the effective component concentration in mixtures under different stimulus conditions.

\section{References}

Barlow R, Blake JF (1989) Hill coefficients and the logistic equation. Trends Pharmacol Sci 10:440-441. CrossRef Medline
Cenier T, McGann JP, Tsuno Y, Verhagen JV, Wachowiak M (2013) Testing the sorption hypothesis in olfaction: a limited role for sniff strength in shaping primary odor representations during behavior. J Neurosci 33:7992. CrossRef Medline

Cometto-Muñiz JE, Cain WS, Abraham MH (2003) Quantification of chemical vapors in chemosensory research. Chem Senses 28:467-477. CrossRef Medline

Coppola DM, Waggener CT, Radwani SM, Brooks DA (2013) An electroolfactogram study of odor response patterns from the mouse olfactory epithelium with reference to receptor zones and odor sorptiveness. J Neurophysiol 109:2179-2191. CrossRef Medline

Curran-Everett D (2000) Multiple comparisons: philosophies and illustrations. Am J Physiol Regul Integr Comp Physiol 279:R1-R8. Medline

Diaz ME (2004) Comparison between orthonasal and retronasal flavour preception at different concentrations. Flavour Frag J 19:499-504. CrossRef

Grosmaitre X, Vassalli A, Mombaerts P, Shepherd GM, Ma M (2006) Odorant responses of olfactory sensory neurons expressing the odorant receptor MOR23: a patch clamp analysis in gene-targeted mice. Proc Natl Acad Sci U S A 103:1970-1975. CrossRef Medline

Hornung DE, Youngentob SL, Mozell MM (1987) Olfactory mucosa/air partitioning of odorants. Brain Res 413:147-154. CrossRef Medline

Hummel T (2008) Retronasal perception of odors. Chem Biodivers 5:853861. CrossRef Medline

Iwema CL, Fang H, Kurtz DB, Youngentob SL, Schwob JE (2004) Odorant receptor expression patterns are restored in lesion-recovered rat olfactory epithelium. J Neurosci 24:356-369. CrossRef Medline

Jiang J, Zhao K (2010) Airflow and nanoparticle deposition in rat nose under various breathing and sniffing conditions: a computational evaluation of the unsteady effect. J Aerosol Sci 41:1030-1043. CrossRef Medline

Johnson BA, Arguello S, Leon M (2007) Odorants with multiple oxygencontaining functional groups and other odorants with high water solubility preferentially activate posterior olfactory bulb glomeruli. J Comp Neurol 502:468-482. CrossRef Medline

Kauer JS, Moulton DG (1974) Responses of olfactory bulb neurones to odour stimulation of small nasal areas in the salamander. J Physiol 243: 717-737. Medline

Kimbell JS, Godo MN, Gross EA, Joyner DR, Richardson RB, Morgan KT (1997) Computer simulation of inspiratory airflow in all regions of the F344 rat nasal passages. Toxicol Appl Pharmacol 145:388-398. CrossRef Medline

Kurtz DB, Zhao K, Hornung DE, Scherer P (2004) Experimental and numerical determination of odorant solubility in nasal and olfactory mucosa. Chem Senses 29:763-773. CrossRef Medline

Landis BN, Giger R, Ricchetti A, Leuchter I, Hugentobler M, Hummel T, Lacroix JS (2003) Retronasal olfactory function in nasal polyposis. Laryngoscope 113:1993-1997. Medline

Lawson MJ, Craven BA, Paterson EG, Settles GS (2012) A computational study of odorant transport and deposition in the canine nasal cavity: implications for olfaction. Chem Senses 37:553-566. CrossRef Medline

Mackay-Sim A, Shaman P, Moulton DG (1982) Topographic coding of olfactory quality: odorant-specific patterns of epithelial responsivity in the salamander. J Neurophysiol 48:584-596. Medline

Marchand JE, Yang X, Chikaraishi D, Krieger J, Breer H, Kauer JS (2004) Olfactory receptor gene expression in tiger salamander olfactory epithelium. J Comp Neurol 474:453-467. CrossRef Medline

Miyamichi K, Serizawa S, Kimura HM, Sakano H (2005) Continuous and overlapping expression domains of odorant receptor genes in the olfactory epithelium determine the dorsal/ventral positioning of glomeruli in the olfactory bulb. J Neurosci 25:3586-3592. CrossRef Medline

Moulton DG (1976) Spatial patterning of response to odors in the peripheral olfactory system. Physiol Rev 56:578-593. Medline

Mozell MM (1964) Evidence for sorption as a mechanism of the olfactory analysis of vapours. Nature 203:1181-1182. CrossRef Medline

Mozell MM (1970) Evidence for a chromatographic model of olfaction. J Gen Physiol 56:46-63. CrossRef Medline

Mozell MM, Jagodowicz M (1973) Chromatographic separation of odorants by the nose: retention times measured across in vivo olfactory mucosa. Science 181:1247-1249. CrossRef Medline

Pfaar O, Landis BN, Frasnelli J, Hüttenbrink KB, Hummel T (2006) Mechanical obstruction of the olfactory cleft reveals differences between or- 
thonasal and retronasal olfactory functions. Chem Senses 31:27-31. Medline

Ressler KJ, Sullivan SL, Buck LB (1993) A zonal organization of odorant receptor gene expression in the olfactory epithelium. Cell 73:597-609. CrossRef Medline

Ressler KJ, Sullivan SL, Buck LB (1994) Information coding in the olfactory system: evidence for a stereotyped and highly organized epitope map in the olfactory bulb. Cell 79:1245-1255. CrossRef Medline

Rospars JP, Lansky P, Chaput M, Duchamp-Viret P (2008) Competitive and noncompetitive odorant interactions in the early neural coding of odorant mixtures. J Neurosci 28:2659-2666. CrossRef Medline

Schoenfeld TA, Cleland TA (2005) The anatomical logic of smell. Trends Neurosci 28:620-627. CrossRef Medline

Schoenfeld TA, Cleland TA (2006) Anatomical contributions to odorant sampling and representation in rodents: zoning in on sniffing behavior. Chem Senses 31:131-144. Medline

Scott JW (2006) Sniffing and spatiotemporal coding in olfaction. Chem Senses 31:119-130. Medline

Scott JW, Brierley T (1999) A functional map in rat olfactory epithelium. Chem Senses 24:679-690. CrossRef Medline

Scott JW, Davis LM, Shannon D, Kaplan C (1996) Relation of chemical structure to spatial distribution of sensory responses in rat olfactory epithelium. J Neurophysiol 75:2036-2049. Medline

Scott JW, Shannon DE, Charpentier J, Davis LM, Kaplan C (1997) Spatially organized response zones in rat olfactory epithelium. J Neurophysiol 77: 1950-1962. Medline

Scott JW, Brierley T, Schmidt FH (2000) Chemical determinants of the rat electro-olfactogram. J Neurosci 20:4721-4731. Medline

Scott JW, Acevedo HP, Sherrill L (2006) Effects of concentration and sniff flow rate on the rat electroolfactogram. Chem Senses 31:581-593. CrossRef Medline
Scott JW, Acevedo HP, Sherrill L, Phan M (2007) Responses of the rat olfactory epithelium to retronasal air flow. J Neurophysiol 97:1941-1950. CrossRef Medline

Sun BC, Halpern BP (2005) Identification of air phase retronasal and orthonasal odorant pairs. Chem Senses 30:693-706. CrossRef Medline

Vassar R, Ngai J, Axel R (1993) Spatial segregation of odorant receptor expression in the mammalian olfactory epithelium. Cell 74:309-318. CrossRef Medline

Vassar R, Chao SK, Sitcheran R, Nuñez JM, Vosshall LB, Axel R (1994) Topographic organization of sensory projections to the olfactory bulb. Cell 79:981-991. CrossRef Medline

Wachowiak M (2011) All in a sniff: olfaction as a model for active sensing. Neuron 71:962-973. CrossRef Medline

Welty JR, Wicks GE, Wilson RE (1976) Fundamentals of momentum, heat and mass transfer, second edition. New York: Wiley.

Wilkes FJ, Laing DG, Hutchinson I, Jinks AL, Monteleone E (2009) Temporal processing of olfactory stimuli during retronasal perception. Behav Brain Res 200:68-75. CrossRef Medline

Yang GC, Scherer PW, Zhao K, Mozell MM (2007) Numerical modeling of odorant uptake in the rat nasal cavity. Chem Senses 32:273-284. CrossRef Medline

Youngentob SL, Mozell MM, Sheehe PR, Hornung DE (1987) A quantitative analysis of sniffing strategies in rats performing odor detection tasks. Physiol Behav 41:59-69. CrossRef Medline

Zhao K, Scherer PW, Hajiloo SA, Dalton P (2004) Effect of anatomy on human nasal air flow and odorant transport patterns: implications for olfaction. Chem Senses 29:365-379. CrossRef Medline

Zhao K, Dalton P, Yang GC, Scherer PW (2006) Numerical modeling of turbulent and laminar airflow and odorant transport during sniffing in the human and rat nose. Chem Senses 31:107-118. Medline 